\title{
Prototype Monitoring of IoT-based Laboratory Firefighting System
}

\author{
Setiaji Cahyadi ${ }^{1}$, Joni Karman ${ }^{2, *}$, Muhammad Nur Alamsyah ${ }^{2}$ \\ ${ }^{1}$ Fakultas Komputer, Program Studi Rekayasa Sistem Komputer, Universitas Bina Insan, Lubuklinggau, Indonesia \\ ${ }^{2}$ Fakultas Komputer, Program Studi Sisitem Informasi,Universitas Bina Insan, Lubuklinggau, Indonesia \\ Email: ${ }^{1}$ setiajicahyadi5@gmail.com, ${ }^{2,}$ joni_karman@univbinainsan.ac.id, ${ }^{3}$ mnuralamsyah@ univbinainsan.ac.id \\ Email Penulis Korespondensi: joni_karman@univbinainsan.ac.id \\ Submitted: 22/12/2021; Accepted: 29/12/2021; Published: 31/12/2021
}

\begin{abstract}
Abstrak-Masalah pada penelitian ini adalah belum adanya pemadam kebakaran otomatis yang membantu kinerja pada penjagaan yang bersifat 24 jam sehingga sangat rentan terhadap konsleting atau hubungan pendek listrik yang mengakibatkan kebakaran yang menimbulkan kerugian yang sangat besar baik material maupun immaterial. Penelitian ini menggunakan metode Prototype. Hasil penelitian menunjukkan bahwa perencanaan pembuatan hardware maupun software mengenai perencanaan alat pemadam kebakaran menggunakan board Arduino Uno serta sensor api atau flame sensor dan sensor gas atau MQ2 sensor sebagai landasan dimana hardware tersebut dapat menjadi input pada software Arduino Ide dan terhubung ke wifi Esp2866 sebagai pengendali IOT dan mengontrol ruangan dalam 24 jam dikarenakan alat ini memiliki buzzer sehingga apabila ada api dan asap yang terdeteksi dapat menyalakan sensor lalu timbul suarta peringatan akan adanya bahaya kebakaran.
\end{abstract}

Kata Kunci: Hardware; Software; Flame sensor; MQ2 Sensor; Wifi Esp2866

Abstract- The problem in this study is the absence of automatic firefighters that helps performance on 24-hour safeguards so that it is very susceptible to a short circuit or electrical relations that lead to fires that cause enormous losses both material and immaterial. This research uses the prototype method. The results showed that the planning of making hardware and software regarding planning fire extinguishers using the Arduino Uno board and a fire sensor or flame sensor and a gas sensor or MQ2 Sensor as a foundation where the hardware can be input on the Arduino IDE software and connected to WiFi ESP2866 as a IoT controller and control the room in 24 hours because this tool has a buzzer so that if there is a fire and smoke detected can turn on the sensor and the arm arises, the warning will be a fire hazard.

Keywords: Hardware; Software; Flame sensor; MQ2 Sensor; Wifi Esp2866

\section{PENDAHULUAN}

Kebakaran merupakan peritiswa yang sering terjadi di wilayah padat penduduk seperti perkotaan dan daerah yang mempunyai pusat industri baik industri kecil dan industri besar, dan tidak menutup kemungkinan akan terjadi di lembaga pendidikan seperti sekolah[1]. SMK Yadika Lubuklinggau bergerak dibidang pendidikan yang visi misinya adalah mencerdaskan anak bangsa dibidang pendidikan di Indonesia secara luas dan begitu juga di Lubuklinggau secara khusus. SMK Yadika Lubuklinggau di bawah naungan Yayasan Abdi Karya. Yayasan Abdi Karya atau Yadika memiliki 71 Unit dan satu perguruan tinggi dan mencakup di 9 ( sembilan ) propinsi di Indonesia.

Pada hari Senin tanggal 18 September 2019 terjadi bencana kebakaran pada SMK Yadika 6 di Jaticempaka , Pondok Gede. Kejadian tersebut menurut data yang ada terjadi hubungan pendek listrik atau korsleting listrik pada laboratorium, pemadaman sulit dilakukan dikarenakan lalu lintas cukup padat sehingga keterlambatan dalam penanganan bencana kebakaran sehingga mengakibatkan kerugian materi. Penduduk di sekitar kawasan sekolah akan sulit bila terjadinya kebakaran diwaktu libur sekolah karena warga sekolah tidak berada disekolah, kecuali petugas keamanan yang jumlahnya paling sedikit 2 orang dan paling banyak 3 orang. Petugas keamanan 2 orang di sekolah biasanya merangkap menjadi petugas kebersihan dan menjaga sekolah dalam sehari penuh atau 24 jam dan pembagian tugas mereka adalah jaga pagi dan jaga malam. Hal ini mengakibatkan kelelahan petugas yang merangkap tugas yaitu tugas keamanan dan kebersihan. Sehingga tindakan yang diambil petugas yang 1 orang dalam melakukan pekerjaan akan semakin tidak terarah dan menimbulkan kelalaian dalam pekerjaan. Petugas keamanan yang paling banyak 3 orang akan bertugas secara pembagian tugas yaitu tugas pagi, siang dan malam. Pembagian tugas ini akan memberikan keringanan akan pekerjaan tetapi tidak menutup kemungkinan kelalaian tugas waktu serah terima pekerjaan dari waktu pagi ke waktu siang dan juga dari waktu siang ke waktu malam. Kelalaian tugas selain keamanan dan kebersihan adalah mengecek peruangan. Apakah kabel masih terpasang di panel listrik atau sudah tercabut? ini sering dilalaikan karena penyerahan tugas pada tugas pagi ke siang.

Bencana kebakaran kalau tidak diatasi dengan cepat akan menyebabkan kerugian materi yang sangat besar dan juga akan membahayakan rumah penduduk sekitar serta jiwa manusia. Kebakaran yang terjadi biasanya yang sering terjadi karena hubungan singkat dari jaringan listrik yang ada di dalam gedung atau salah satu ruangan gedung dan kebakaran bisa merambat ke ruangan yang lain[2]. Perkembangan teknologi komunikasi telah mengembangkan dan menciptakan konsep internet-of-things bersamaan tumbuhnya kebutuhan terhadap maha data ( big data) dan komputasi awan ( cloud computing). Dengan konsep tersebut, proses yang diolah oleh sistem akan menjadi lebih efektif dan efesien[1]. Keterkaitan dengan implementasi tersebut, penulis mendeskripsikan tentang prototipe pendekteksi kebakaran menggunakan sistem deteksi kebakaran secara otomatis berbasis platform internet of think. 


\section{METODOLOGI PENELITIAN}

\subsection{Tahapan Penelitian}

Pada penelitian yang dilakukan menggunakan beberapa tahapan, sebagai berikut:

1. Pengumpulan Data

Observasi yang digunakan adalah pendekatan atau teknik supaya mendapatkan data primer dengan pengamatan secara langsung pada objek datanya sehingga data yang diperoleh secara lengkap pada saat terjadinya dan mencatat hasil dari observasi tersebut. Dengan melakukan observasi langsung dapat mencari informasi berupa data baik alat dan bahan serta seua yang digunakan dalam penelitian ini[10]

2. Pembuatan Protype

Untuk tahapan ini penulis mengerjakan desain dari perangkat keras dan perangkat lunak dari sistem monitoring keadaan normal atau tidak normal pada ruangan laboratorium yang berbasis IoT dengan menggunakan Arduino Uno R3

3. Evaluasi prototyping

Bentuk pengujian alat prptotype penulis mengerjakan pengujian dengan pengujian sistem pengujian fungsional pada fungsional prototype.

4. Pembangunan sistem

Pada tahapan ini implementasi dari desain perangkat yang dikerjakan dapat menghasilkan perangkat keras atau hardware dan software atau perangkat lunak yang dibutuhkan yaitu sistem monitoring keadaan normal atau tidak normal pada ruangan laboratorium berbasis IoT dengan menggunakan Arduino Uno R3.

5. Pengujian dan Evaluasi Sistem

Bentuk pengujian alat prptotype penulis mengerjakan pengujian dengan pengujian sistem pengujian fungsional pada fungsional prototype.

6. Penggunan Sistem

Analisa sistem suatu penelitian dapat menjelaskan tentang cara kerja Alat Pemadam Kebakaran berbasis IOT dengan menggunakan Arduino Uno yang menggunakan mikrokontroler Atmega328P. Sistem yang dirancang dapat digunakan untuk mengukur keadaan suhu disuatu ruangan dengan menerapkan kondisi suatu ruangan, yaitu:

a. Ketika hasil dari data informasi sensor api dan sensor $M Q 2$ pada ruangan array akan langsung mengaktifkan pompa mini karena adanya sumber api dan gas yang terdeteksi[4].

b. Ketika hasil dari data informasi sensor api dan sensor $M Q 2$ pada ruangan kemudian pompa mini hidup dan akan dimatikan diaplikasi Blynk sebagai saklar IOT yang menonkan pada pompa mini tersebut[4].

Gambar dibawah ini menunjukkan flowchart Alat Pemadam Kebakaran berbasis IOT.

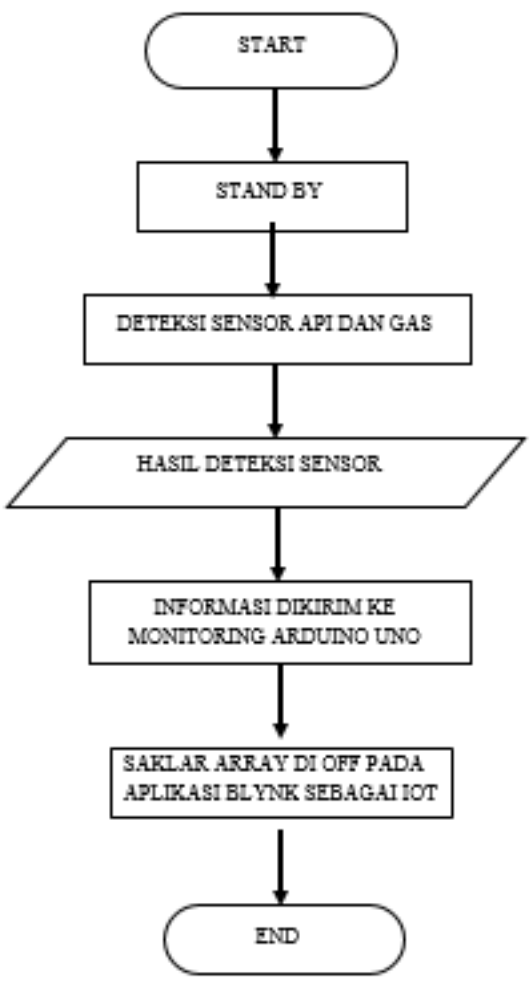

Gambar 1. Flowchart Sistem Yang Dirancang 


\subsection{Model prototipe}

Pemodelan prototipe dapat dilakukan pada sisi fungsional dari bagian perangkat yaitu pada perangkat keras atau hardware dan perangkat lunak atau software dari Alat Pemadam Kebakaran berbasis IOT menggunakan Arduino Uno yang mempunyai mikrokontroler Atmega328P di SMK Yadika Lubuklinggau, berikut ini model perancangan penguji perangkat-perangkat yang akan dilakukan:

Tabel 1. Perancangan Penguji Prototipe Alat Pemadam Kebakaran

\begin{tabular}{|c|c|c|c|}
\hline No & $\begin{array}{l}\text { Komponen } \\
\text { Pengujian }\end{array}$ & Proses Pengujian & $\begin{array}{l}\text { Hasil Pengujian } \\
\text { diharapkan }\end{array}$ \\
\hline \multicolumn{4}{|c|}{ Pengujian Perangkat Keras } \\
\hline 1 & Flame Sensor / Sensor api & $\begin{array}{l}\text { Melakukan pengambilan data informasi } \\
\text { adanya api dari ruangan laboratorium; }\end{array}$ & $\begin{array}{l}\text { Sensor mendeteksi akan adanya } \\
\text { api pada ruangan; }\end{array}$ \\
\hline 2 & Sensor asap $M Q-2$ & $\begin{array}{l}\text { Melakukan pengambilan data informasi } \\
\text { akan adanya asap dari ruangan } \\
\text { laboratorium; }\end{array}$ & $\begin{array}{l}\text { Sensor akan mendeteksi akan } \\
\text { adanya asap pada ruangan; }\end{array}$ \\
\hline 3 & Arduino Uno & $\begin{array}{l}\text { Melakukan proses terhadap data yang } \\
\text { telah diambil oleh sensor; }\end{array}$ & Tampilan dari hasil sensor; \\
\hline 4 & Modul Wifi ESP8266 & $\begin{array}{l}\text { Mengirimkan data informasi serial } \\
\text { TCP/IP dan mengubah kembali data } \\
\text { informasi yang diterima melalui IP ke } \\
\text { dalam bentuk serial; }\end{array}$ & $\begin{array}{l}\text { Proses koneksi dalam transfer } \\
\text { data serial; }\end{array}$ \\
\hline 5 & Smartphone & $\begin{array}{l}\text { Menampilkan hasil pembacaan sensor } \\
\text { setelah diproses oleh Arduino Uno R3 } \\
\text { yang memiliki mikrokontroler; }\end{array}$ & $\begin{array}{l}\text { Tampilan data dalam visualisai } \\
\text { interfacing blynk; }\end{array}$ \\
\hline \multicolumn{4}{|c|}{ Pengujian Perangkat Lunak } \\
\hline 1 & Perintah baca data sensor; & $\begin{array}{l}\text { Melakukan inisialisasi input terhadap } \\
\text { sensor; }\end{array}$ & $\begin{array}{l}\text { Berhasil melakukan inisialisasi } \\
\text { input sensor; }\end{array}$ \\
\hline 2 & $\begin{array}{l}\text { Perintah respon terhadap } \\
\text { hasil pembacaan sensor; }\end{array}$ & $\begin{array}{l}\text { Melakukan inisialisasi terhadap data } \\
\text { kondisi dari pembacaan sensor; }\end{array}$ & $\begin{array}{l}\text { Berhasil melakukan inisialisasi } \\
\text { terhadap berbagai data kondisi } \\
\text { dari pembacaan sensor; }\end{array}$ \\
\hline 3 & $\begin{array}{l}\text { Perintah mengirimkan data } \\
\text { informasi dari Arduino Uno } \\
\text { yang memiliki mikrontroler; }\end{array}$ & $\begin{array}{l}\text { Melakukan inisialisasi terhadap data } \\
\text { informasi yang dikirim ke modul transfer } \\
\text { data; }\end{array}$ & $\begin{array}{l}\text { Berhasil melakukan inisialisasi } \\
\text { terhadap data informasi yang } \\
\text { dikirim ke model transfer data; }\end{array}$ \\
\hline 4 & $\begin{array}{l}\text { Perintah menampilkan hasil } \\
\text { transfer data informasi ke } \\
\text { blynk; }\end{array}$ & $\begin{array}{l}\text { Melakukan inisialisasi menampilkan hasil } \\
\text { transfer data informasi ke interfacing } \\
\text { blynk; }\end{array}$ & $\begin{array}{l}\text { Berhasil menampilkan hasil } \\
\text { transfer data informasi ke } \\
\text { interfacing blynk; }\end{array}$ \\
\hline
\end{tabular}

Rangkaian elektrik catu daya dapat berfungsi untuk memberikan listrik ke dalam sistem, rangkaian ini mensupply tegangan DC+5V yang akan mensupply untuk modul arduino uno, rangakaian elektrik ini terdiri dari beberapa komponen sebagai berikut:

1. Kapasitor berfungsi sebagai penghilang riak (noise) yang diperoleh hasil dari diode.

2. Transformator step down, difungsikan sebagai penurun tegangan AC $220 \mathrm{~V}$ menjadi $12 \mathrm{~V}$.

3. Dioda, digunakan sebagai penyearah gelombang tegangan listrik AC menjadi tegangan listrik DC.

4. IC U17805, dipakai untuk menghasilkan tegangan listrik konstan $+5 \mathrm{~V}$. Rangkaian dibawah adalah rangkaian elektrik catu daya

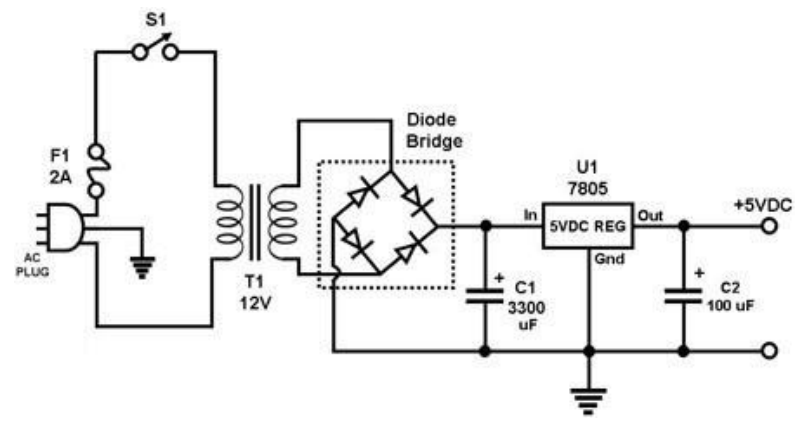

Gambar 1. Rangkaian Elektrik Catu Daya 


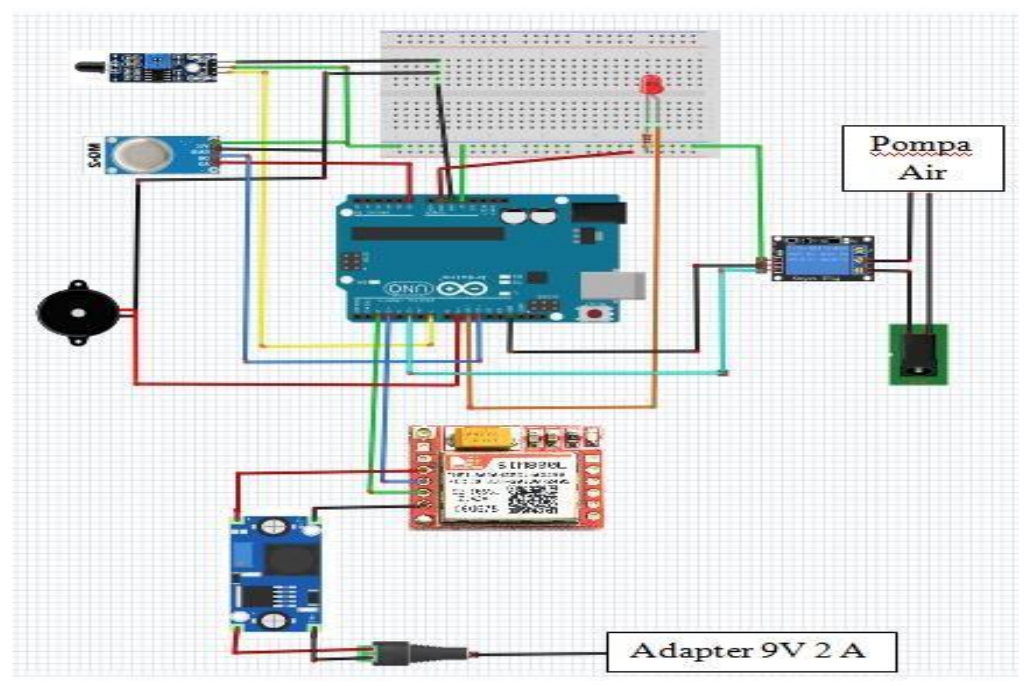

Gambar 2. Skema rangkaian Arduino Uno diujicoba.

Rancangan blink dibawah ini menampilkan hasil dari modul-modul sensor Arduino Uno yang telah berhasil

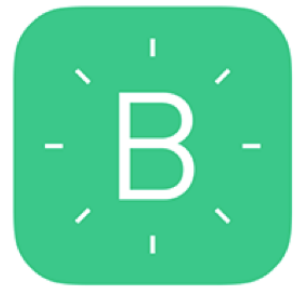

Gambar 3. Perancangan Blynk Android Pemadam Kebakaran

\section{HASIL DAN PEMBAHASAN}

\subsection{Perancangan Sistem}

Perancangan dari sistem pendeteksian pemadam kebakaran pada ruangan menggunakan sensor gas $M Q 2$ dan sensor api atau flame sensor berbasis Arduino Uno dibagi menjadi dua bagian, terdiri dari hasil perancangan lunak dan hasil peracangan perangkat keras. Hasil perancangan lunak perancangan perangkat lunak meliputi instalasi dan coding. Instalasi disini sudah termasuk tahap instalasi Arduino IDE dan Blynk. Sedangkan coding yang akan dimasukkan ke dalam Arduino Uno untuk mengaktifkan sensor suhu sensor asap MQ2 dan sensor api atau flame sensor. Perancangan coding dirancang dengan menggunakan bahasa C, editor Arduino IDE dan Xampp. Sebelum melakukan tahapan coding, maka dilakukan instalasi Arduino Ide dkedalam PC. Sedangkan perancangan perangkat keras, di tekan pada titik perancangan modul input yang berupa modul sensor suhu DHT11, sensor asap MQ2 dan sensor api atau falme sensor. Perancangan modul proses yang berupa modul Arduino Uno dan perancangan modul output di Blink Android

\subsection{Perancangan Perangkat Lunak Sistem Arduino Ide}

Seperti yang dijelaskan secara umum diatas, maka perancangan perangkat lunak sistem meliputi tahapan instalasi Software Arduino IDE yang dapat diunduh secara gratis. Berikut tahapan instalasi Arduino IDE :

1. Sebelumnya download dahulu installer Arduino IDE di https://www.arduino.cc/en/Main/Software.

2. Setelah selesai, jalankan file installer tadi, maka akan muncul licence agreement, klik tombol "I Agree" untuk melanjutkan instalasi'.

3. Berikutnya akan diminta folder instalasi arduino, biarkan dalam posisi default.

4. Setelah itu akan muncul jendela Set Up, sebaiknya centang semua opsi yang ditawarkan.

5. Selanjutnya proses instalasi akan dimulai

6. Ditengah proses instalasi, jika komputer belum terinstal driver USB, maka akan muncul jendela security warning. Pilih tombol install.

7. Tunggu hingga proses instalasi "complete"

8. Pada tahapan ini, software Arduino telah terinstal, jalankan software tersebut sehingga muncul splash screen seperti gambar berikut

9. Beberapa detik kemudian, jendela Arduino IDE akan muncul 
Building of Informatics, Technology and Science (BITS)

Volume 3, No 3, Desember 2021 Page: 412-419

ISSN 2684-8910 (media cetak)

ISSN 2685-3310 (media online)

DOI 10.47065/bits.v3i3.1142

10. Setelah selesai tahapan instalasi arduino IDE, maka selanjutnya akan dilakukan coding. Coding ditulis editor Arduino IDE.

\subsection{Perancangan Perangkat Lunak Sistem Blynk}

Saat sistem pertama kali dijalankan software harus di download di play store pada aplikasi Android.

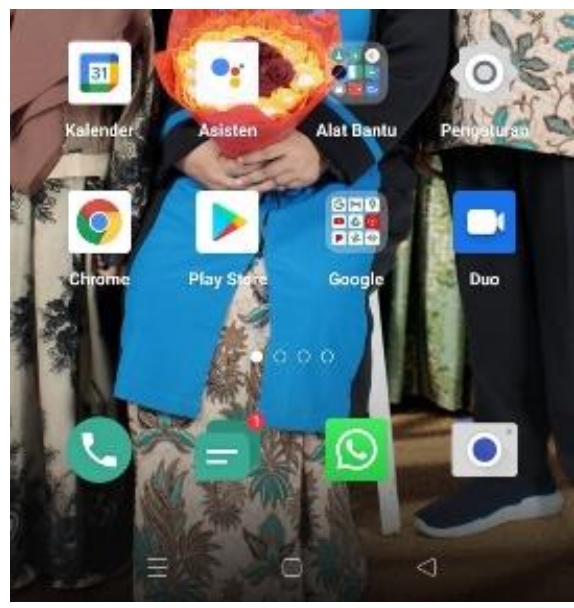

Gambar 4. Tampilan Arduino IDE

Kemudian di download jalan review installer lalu klik tombol Next

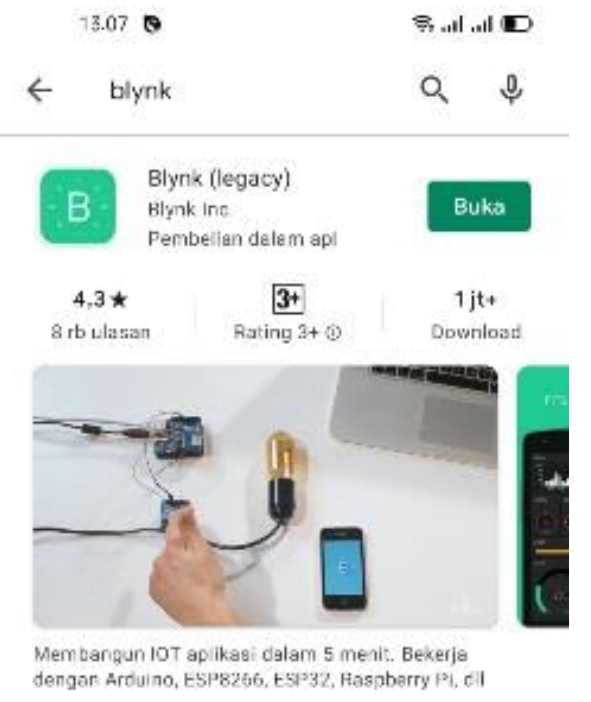

Gambar 5. Tampilan installer Blynk

Pada tampilan klik buka akan tampil gambar 6 .

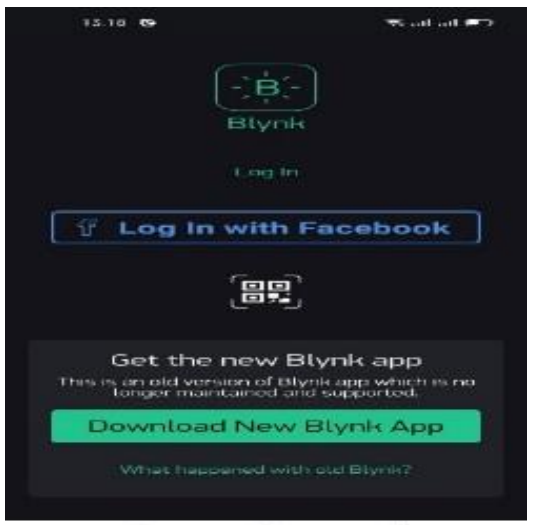

Gambar 6. Tampilan log in Facebook 
Building of Informatics, Technology and Science (BITS)

Volume 3, No 3, Desember 2021 Page: 412-419

ISSN 2684-8910 (media cetak)

ISSN 2685-3310 (media online)

DOI 10.47065/bits.v3i3.1142

Kemudian masuk aplikasi seperti gambar dibawah ini

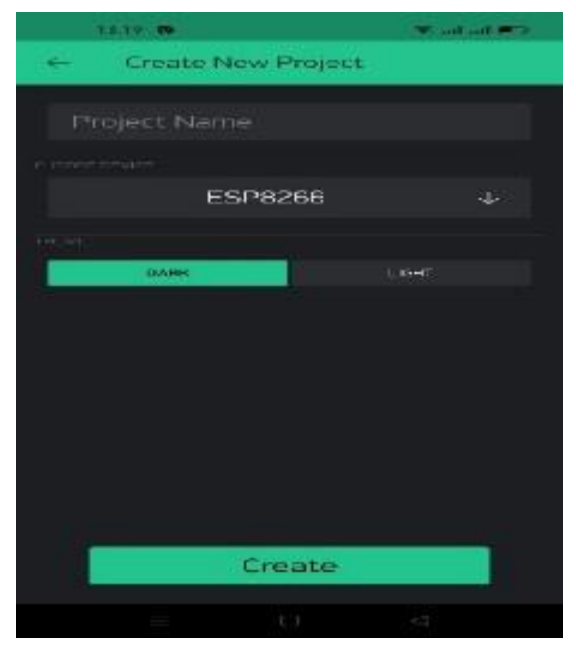

Gambar 7. Tampilan Create New Project

Ketik Create New Project dengan nama alat yang akan di akan dibuat, ada token yang masuk melalui email yang masuk ke aplikasi facebook

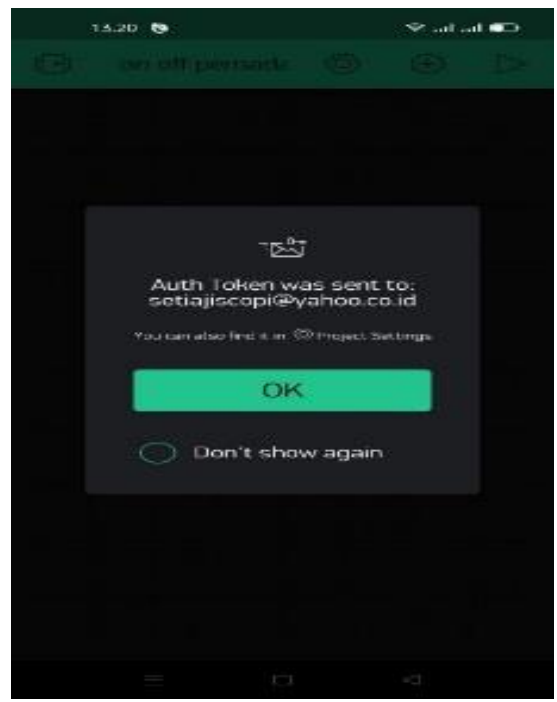

Gambar 8. Tampilan token ke email

Lalu klik finish ketika proses instalasi selesai, seperti pada gambar 9.

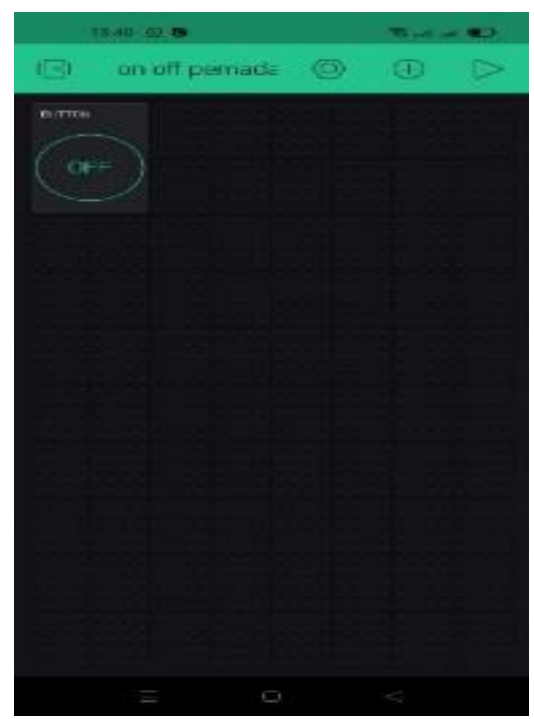

Gambar 9. Tampilan finish pada Blynk 
Building of Informatics, Technology and Science (BITS)

Volume 3, No 3, Desember 2021 Page: 412-419

ISSN 2684-8910 (media cetak)

ISSN 2685-3310 (media online)

DOI 10.47065/bits.v3i3.1142

\subsection{Perancangan Perangkat Keras}

Rancangan Rangakai Modul Arduino Uno adalah sebagai berikut

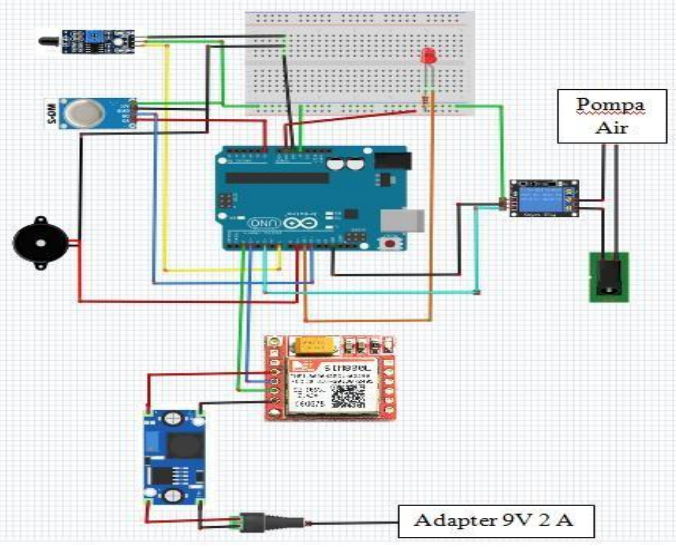

Gambar 10. Skema rangkaian Arduino Uno

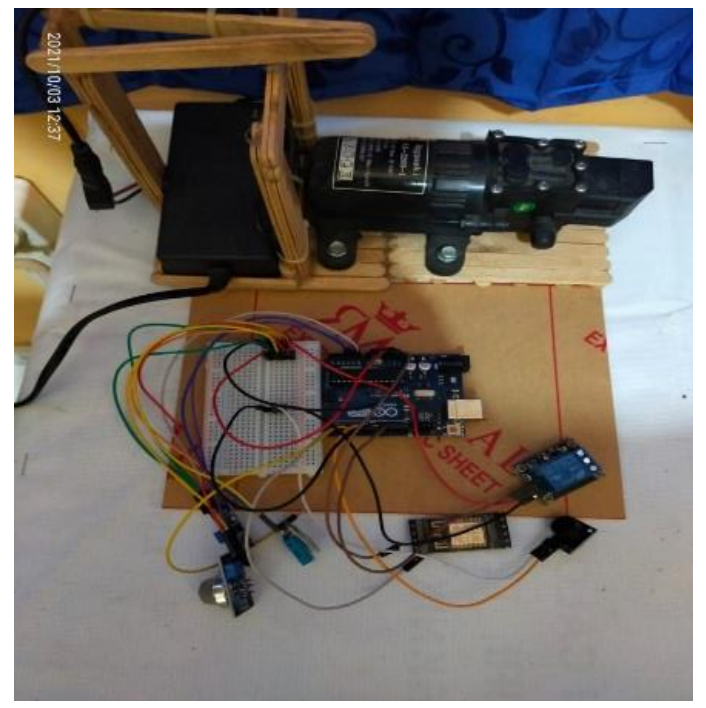

Gambar 11. Skema rangkaian Arduino Uno

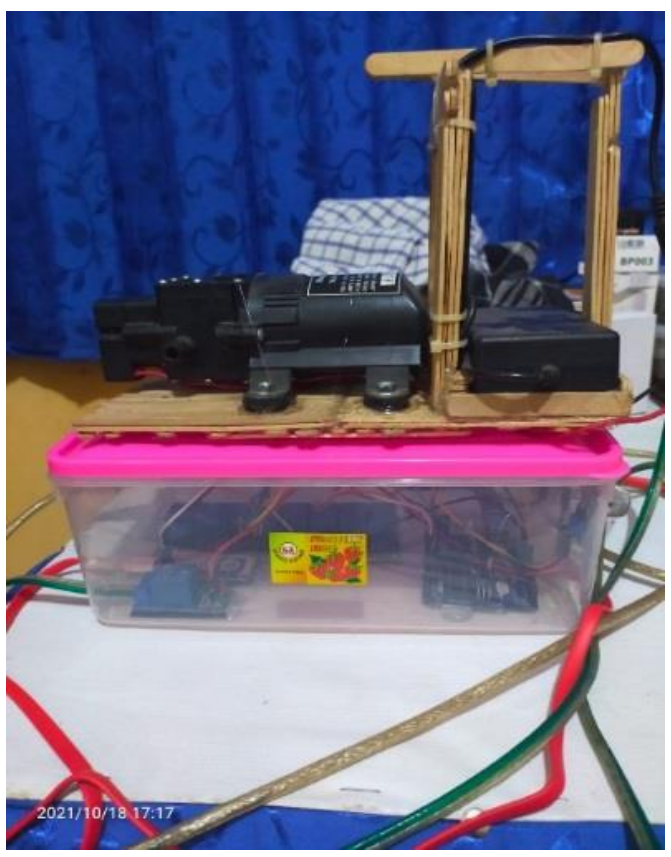

Gambar 12. Alat yang sudah dirakit 


\section{KESIMPULAN}

Dari hasil penelitian disimpulkan sistem alat ini dapat diterapkan dalam melakukan pengambilan data informasi suhu ruangan, adanya api, serta asap dengan menggunakan modul-modul sensor yaitu modul sensor api atau flame sensor, sensor asap $M Q-2$ dan modul Adruino Uno. Alat dapat digunakan dalam transmisikan data informasi dari Arduno Uno ke Android untuk divisulisasikan diaplikasi Blynk.

\section{REFERENCES}

[1] Kusnandar and N. K. H. D. D. A. Pratika, "Rancang Bangun Prototipe Pendeteksi Kebakaran Menggunakan Konsep Internetof-Things," J. Tek. Media Pengemb. Ilmu dan Apl. Tek., vol. 18, no. 01, pp. 1412-8810, 2019.

[2] dkk. 2017 Mega Apriyaningsih, "Prototipe Sistem Pemadam Kebakaran Otomatis," Prototipe Sist. Pemadam Kebakaran Otomatis Berbas. Mikrokontroler Atmega328p, vol. V, no. 3, pp. 106-110, 2017.

[3] D. Sasmoko and A. Mahendra, "RANCANG BANGUN SISTEM PENDETEKSI KEBAKARAN BERBASIS IOT DAN SMS GATEWAY MENGGUNAKAN ARDUINO,” vol. 8, no. 2, pp. 469-476, 2017.

[4] F. Nur Rohim et al., "SIMULASI ALAT PENDETEKSI KEBAKARAN MENGGUNAKAN SENSOR ASAP MQ2, SENSOR SUHU LM35, DAN MODUL WIFI ESP8266 BERBASIS MIKROKONTROLER ARDUINO.”

[5] W. P. Bahari and A. Sugiharto, "RANCANG BANGUN ALAT PENDETEKSI KEBAKARAN BERBASIS INTERNET OF THINGS ( IoT )."

[6] N. S. Rahayu et al., "Rancang Bangun Sistem Pemadam Kebakaran Otomatis dan Dinamis Berbasis Mikrokontroler," vol. 6, no. 3, pp. 290-295, 2017.

[7] S. S. Dewi, D. Satria, E. Yusibani, and D. Sugiyanto, "Prototipe Sistem Informasi Monitoring Kebakaran Bangunan Berbasis Google Maps dan Modul GSM," vol. 1, no. 1, 2017.

[8] Junaidi and Y. D. Prabowo, Project Sistem Kendali Elektronik Berbasis Arduino. 2018.

[9] R. N. Yanuar, M. Hannats, H. Ichsan, and G. E. Setyawan, "Implementasi Sistem Pemadam Kebakaran Pada Ruang Tertutup Berbasis Arduino Menggunakan Logika Fuzzy," vol. 3, no. 4, 2019.

[10] D. Prasanti, "Penggunaan Media Komunikasi Bagi Remaja Perempuan Dalam Pencarian Informasi Kesehatan," LONTAR J. Ilmu Komun., vol. 6, no. 1, pp. 13-21, 2018, doi: 10.30656/lontar.v6i1.645. 